\title{
AWARENESS VERSUS UN-CLINGING: WHICH MATTERS IN MINDFULNESS?
}

\author{
Siu-man Nga , King Wo Chow ${ }^{b}$, Hi Po Lau a and Qi Wanga
}

${ }^{\mathrm{a} D e p a r t m e n t ~ o f ~ S o c i a l ~ W o r k ~ a n d ~ S o c i a l ~ A d m i n i s t r a t i o n, ~ T h e ~ U n i v e r s i t y ~ o f ~ H o n g ~ K o n g ; ~}{ }^{\mathrm{b}}$ Department of Psychology, The Chinese University of Hong Kong

\section{ABSTRACT}

Awareness and un-clinging have been emphasised in Buddhist discourse as important facets of mindfulness practice for over 2500 years. However, there is a lack of rigorous research examining the relationship between these two elements and their importance to well-being. To evaluate these abstract constructs, the current study adopted multiple assessment modalities; namely, a self-report scale, experience sampling (assessing 'momentary mindfulness'), and semi-structured interviews (assessing 'rater-rated mindfulness'). A total of 415 participants completed the questionnaire survey. Among them, 71 participants further took part in the experience sampling procedure and semi-structured interviews. The findings reveal that self-reported awareness was mildly correlated with momentary mindfulness ( $r=.35$ ) but was not significantly correlated with raterrated mindfulness. Self-reported un-clinging was moderately correlated with raterrated mindfulness $(r=.53)$ but was not significantly correlated with momentary mindfulness. Un-clinging, but not awareness, can distinguish meditators from non-meditators. Lastly, based on the Buddha's mindfulness discourse, a path analysis model illustrates that the effects of un-clinging and awareness on stress reduction are mediated by emotional intelligence and non-attachment. Practical implications and future research designs are discussed.

Despite the widespread applications of mindfulness-based interventions, to date, there is no consensus regarding the defining criteria of mindfulness (Mooneyham et al. 2016). Researchers have debated whether mindfulness should be conceptualised as purely the manifestation of consciousness or as a multifaceted construct involving different attitudes and skills, such as awareness, acceptance, ethics and un-clinging (Smith, Fischer, and Fister 2003; Brown, Ryan, and Creswell 2007a, 2007b; Ivanovski and Malhi 2007; Smith et al. 2007; Baer et al. 2008; Mikulas 2010). Some scholars critique the core awareness component of current mindfulness conceptualisations as being significantly watered down in both breadth and clarity, compared to the original Buddhist texts (Rapgay and Bystrisky 2009; Mikulas 2010; Grossman 2011). 
Kabat-Zinn (2003, 2011), the founder of the Mindfulness-Based Stress Reduction (MBSR) program, has emphasised the way in which mindfulness-based interventions should be consistent with the universal Buddha dharma, although these interventions are not constrained by Buddhist traditions. The original intention of developing the MBSR program was to incorporate mindfulness practice into the framework of modern health care sciences. Nevertheless, the hugely popular MBSR program is often criticised as being a substantially decontextualised form of Buddhist mindfulness practice (Rapgay and Bystrisky 2009; Mikulas 2010; Grossman 2011). In the light of these controversies, the current study attempted to re-examine the components and facets of mindfulness, based on the Buddha dharma.

\section{Buddhist mindfulness}

In one of the most recognised and comprehensive mindfulness practices related to the Buddha's discourse, the Mahä-Satipațthāna Sutta (Nyanaponika 1962;

15 Kabat-Zinn 2003), the Buddha stated the definition of mindfulness and repeated it 21 times throughout the whole discourse. The Buddha's conceptualisation of mindfulness includes the following elements: (1) Sustaining: 'remain focused' (Nyanaponika 1962, 129); (2) Expanding: cover all perceptible experiences, including 'body, feeling, mind, and mental qualities' (130); (3) Discerning:'remain focused on the phenomenon of origination and passing away with regard to the body, feeling, mind, and mental qualities' (130); and (4) Un-clinging (to the internal body, feeling, mind, and mental qualities) and non-attachment (to the external world):'his mindfulness that "there is a body, feeling, mind, and mental qualities" is maintained to the extent of knowledge and remembrance and he remains independent, unsustained by (not clinging to) anything in the world' (Nyanaponika 1962, 130; Thanissaro 2011).

In the Mahä-Satipațhana Sutta, the Buddha emphasised the way in which mindfulness practice should bring awareness and discernment to perceptible physical and psychological functioning. In the mental qualities section in particular, the Buddha highlighted the way in which one should discern how different adaptive and maladaptive experiences appear and disappear, so as to maximise the adaptive ones and abandon the maladaptive ones. At the same time, as emphasised by the 21 iterations of the definition of mindfulness, one should maintain un-clinging in regard to all these internal functions and non-attachment to the external world. This will ultimately lead to stress reduction (Thanissaro 2011). This paper focused on examining the two integral elements of mindfulness: awareness and un-clinging. 


\section{Awareness}

There are different understandings of awareness in the Buddhist tradition of mindfulness and in Western psychology. Awareness was characterised in Buddhist discourse as a continuous monitoring of the totality of the current experience, rather than past or future events (Dreyfus, 2011; Cardaciotto et al. 2008; Deikman 1996; Roemer and Orsillo 2003). According to Buddhist discourse, it is equally important for an individual to stay in wholesome and in unwholesome mental states while examining the beneficial or detrimental nature of various mental states (Mendis 1993; Dreyfus, 2011). One should pay close attention to an object and make sense of one's own perceptions and cognitive processes (Jha et al. 2010). Mindfulness is more than an awareness of an object's existence. In the Satipatthanna Sutta, mindfulness was described in detail as involving 'the mind's ability to attend to and retain whatever experience one is engaged in, so as to develop a clear understanding of the experience and the ability to recollect such experiences in the future' (Dreyfus, 2011, 48).

In Western psychology, awareness is often defined as simply observing the contents and processes of one's mind without thinking, judging or categorising (Mikulas 2010). In addition to this, the essence of awareness cultivation in mindfulness training is to notice things that arise in one's consciousness while 'minimising the occurrence of getting lost in related thoughts, reactions, and elaborations' (Mikulas 2010, 6). This underscores the discrepancy between the understandings of awareness in mindfulness in Buddhist and Western psychology. In Buddhist discourses, awareness is for the pursuit of both discernment/ understanding and peacefulness/calmness, whereas, in Western mindfulness interventions, awareness is primarily for the pursuit of just peacefulness/ calmness.

\section{Un-clinging}

Based on the Four Noble Truths, suffering and dissatisfaction are caused by clinging to internal phenomena and attachment to external objects, including sensations, perceptions, beliefs, expectations, opinions, rituals, images of the self and models of reality (Mikulas, 2011). Clinging and attachment lead to resistance to change and distortions in perceptions, memories and thinking (Rahula 1974). Clinging is considered to be a hindrance to understanding the truth or reaching awakening (Rahula 1974). In Buddhism, un-clinging is a way to deeper levels of mindfulness, leading to acceptance, non-reactivity, self-compassion, subjective well-being and, ultimately, eudemonic well-being (Sahdra, Shaver, and Brown 2010) and the end of suffering, which are the goals of practicing mindfulness (Komagata and Komagata 2010). 


\section{The current study: re-examining the relationship between awareness and un-clinging}

Buddhism sees both awareness and un-clinging as indispensable steps in mindfulness practice and relief from suffering. Western psychology mainly emphasises just the power of awareness in stress reduction; the role of un-clinging has received relatively less attention. While the discrepancy between Buddhism and Western psychology in regard to understanding awareness and un-clinging has been discussed by some scholars, rigorous studies delineating the relationship between the two central elements are still lacking.

Based on the Mahä-Satipațthāna Sutta, we propose that: (i) awareness and un-clinging are distinguishable elements of mindfulness; (ii) un-clinging, which creates freedom from negative emotions, is more strongly associated with well-being and stress reduction than mere awareness is; and (iii) un-clinging and awareness together result in autogenic effects through the facilitation of psychological discernment and non-attachment to the material world.

Most research in the mindfulness literature relies on self-report scales to measure mindfulness. However, over-reliance on self-report mindfulness scales may obscure the distinctiveness of various elements, including awareness and un-clinging. Hence, we first assessed awareness and un-clinging using multiple assessment modalities. We hypothesised that awareness would be more strongly associated than un-clinging with momentary mindfulness measured through experience sampling, whereas un-clinging would be more strongly associated than awareness with mindfulness levels obtained through interviews involving negative emotional scenarios. We explored the association of awareness and un-clinging with mental health outcomes. We predicted that un-clinging would be more strongly associated with the alleviation of suffering than awareness would. The efficacy of awareness and un-clinging in distinguishing meditators and non-meditators was also explored.

According to the original Buddhist discourse of mindfulness, a hypothesised model that describes the relationships among awareness, un-clinging, discernment (captured by emotional intelligence), non-attachment (captured by the



Figure 1. Hypothesised path and mediation model from mindfulness to stress reduction, based on the Buddha's mindfulness discourse. 
over-attachment component in Chinese medicine stagnation syndrome, on which see below), and perceived stress are constructed accordingly and tested empirically, using path analysis. Figure 1 illustrates the conceptual model. It is important to note that un-clinging is conceptually different from non-attachment. Un-clinging concerns internal thoughts, emotions and sensations, while non-attachment concerns external world affairs and matters. The Buddha's mindfulness practice discourse describes the way in which awareness and un-clinging regarding the internal body, mind and senses bring about discernment and non-attachment to the external world, which leads to stress reduction.

Emotional intelligence was used to capture discernment because it reflects one's ability to recognise and regulate one's emotions. Over-attachment, a core element of Chinese medicine stagnation syndrome, is used to capture non-attachment because it reflects one's inability to let go of external affairs and clinging to what one possesses ( $\mathrm{Ng}$ et al., 2017). It matches the Buddha's emphasis on non-attachment to external world matters and affairs.

\section{Methods}

\section{Participants and procedures}

All participants were recruited online or through referrals. After providing their consent on the introductory page of the online survey, participants were asked

20 to complete a battery of questionnaires on mindfulness and mental health outcomes, which took approximately $30 \mathrm{~min}$. Since the promotion of the survey targeted postgraduate students and communities interested in Buddhism and mindfulness practice, the study sample was over-represented in younger adults with tertiary education, Buddhists, and meditators.

25 There were a total of 415 participants in this study; $74.9 \%$ of them were women, $45.3 \%$ were under $30,88.9 \%$ had tertiary education, $55.2 \%$ were working full-time and $43.1 \%$ were meditators. About half of the participants (52.5\%) were not affiliated with any religion, whereas $22.6 \%$ were Buddhist and $21.9 \%$ were Catholic/Christian.

30 Among the 415 participants, 71 further agreed to participate in a two-day sampling procedure and a 30-min mindfulness interview. Ethical approval was sought and granted by the Human Research Ethics Committee for Non-Clinical Faculties, The University of Hong Kong.

\section{Measures}

\section{Awareness}

Awareness was measured by the Body-Mind-Senses Awareness Scale (Chow 2015). It is a three-factor, 14-item scale used to measure individuals' awareness of the mind, senses, and body. It is rated on a five-point scale that ranges from 'never aware' to 'continuously aware' of the present moment of the mind, senses 
and body. The scale showed satisfactory internal consistency, with Cronbach's alphas of 0.88 for the whole scale and $0.75-0.88$ for the two subscales.

\section{Un-clinging}

Un-clinging was assessed by the Greed-Distress Un-Clinging Scale (Chow 2015). It is a five-item scale used to measure participants' levels of clinging to unhappy emotions, thoughts, sensations, psychological responses and desires. It is rated on a five-point scale that ranges from 'never gets caught or indulges in them' to 'totally get caught or indulges in them'. The scale showed satisfactory internal consistency, with a Cronbach's alpha of 0.86 .

\section{Mental health outcomes}

The Body-Mind-Spirit Well-Being Inventory (BMSWBI; Ng et al. 2005) is a four-factor, 56-item self-report scale measuring holistic well-being. It has demonstrated satisfactory internal consistency, with Cronbach's alphas ranging from 0.87 to 0.92. Higher scores indicate better overall well-being. In the current study, only the Physical Distress and the Positive and Negative Affect subscales were used.

The Emotional Intelligence Scale (EIS; Wong and Law 2002) is a four-factor, 16-item scale measuring one's ability to identify and regulate one's own emotions. The four factors are: Self Emotion Appraisal, Others Emotion Appraisal, Use of Emotion and Emotion Regulation. It is rated on a six-point scale that ranges from 'strongly disagree' to'strongly agree'. The Chinese version of the EIS demonstrated satisfactory internal consistency, with Cronbach's alphas ranging from 0.70 to 0.85 in the Hong Kong population.

The Stagnation Scale (SS; Ng et al. 2012, 2005) is a three-factor, 16-item scale measuring traditional Chinese medicine stagnation syndrome, which is characterised by a cluster of mind/body obstruction-like symptoms. The three subscales are: Over-Attachment, Body-Mind Obstruction and Affect-Posture Inhibition. The SS demonstrated satisfactory internal consistency, with Cronbach's alphas of 0.91 for the whole scale and $0.82-0.88$ for the three subscales.

Underwood's Daily Spiritual Experience Scale (DSES; Underwood and Teresi 2002) is a single-factor, 16-item scale measuring one's interaction with 'God' in day-to-day life. To embrace people with non-religious stances, the Chinese version of the DSES (CDSES; Ng et al. 2009) extends the term 'God' to include both philosophical and humanised higher powers. A corresponding explanatory note for the term 'God' is added in the Chinese version. The CDSES has been validated in Hong Kong and demonstrated good internal consistency, with a Cronbach's alpha of 0.97 .

The Perceived Stress Scale (PSS; Cohen, Kamarck, and Mermelstein 1983) is a two-factor, 10-item scale measuring stress. It is rated on a five-point scale that ranges from 'never' to 'very often'. The two factors are Perceived Helplessness internal consistency, with Cronbach's alphas ranging from 0.67 to 0.78 ( $\mathrm{Ng} \mathrm{2013).}$ 
The Satisfaction with Life Scale (SWLS; Diener et al. 1985) is a single-factor, five-item scale measuring global judgements of quality of life and general perceptions of life satisfaction. It is rated on a seven-point scale that ranges from 'strongly disagree' to 'strongly agree'. The SWLS showed satisfactory internal consistency, with Cronbach's alphas ranging from 0.79 to 0.89 (Vera-Villarroel et al. 2012).

\section{Experience sampling of mindfulness}

Using prompts on mobile phones, momentary mindfulness was measured by four short questions, which assess here-and-now mindfulness towards the body, 10 thoughts, emotions and environment (corresponding to the body, mind and senses; Chow 2015). Measurements were taken three times a day (morning, afternoon and night) for two consecutive days. The scores of the four questions were summed to give a total mindfulness score at each time point. The measure showed satisfactory internal consistency, with a Cronbach's alpha of 0.88 .

\section{Rater-rated mindfulness}

The interview schedule was modified from the Measure of Awareness and Coping in Autobiographical Memory (MACAM; Moore, Hayhurst, and Teasdale 1996) manual. During the interviews, participants were asked to respond to three negative emotion scenarios. The interviews were audiotaped and the responses of the participants were rated by a rater. The measure showed fair internal consistency, with Cronbach's alphas ranging from 0.47 to 0.49 (Teasdale et al. 2002; Chow 2015).

\section{Results}

\section{Distinguishing awareness and un-clinging using multiple assessment} modalities

The unadjusted correlation between un-clinging and awareness was non-significant $(r=.110)$, suggesting that the two are independent constructs. This implies that people with high levels of awareness may still become over-attached to their greed and distress, whereas people with low levels of awareness may not tend to be attached to their greed and distress. After adjusting for the effects of the self-emotion appraisal score, awareness was negatively associated with un-clinging levels ( $B=-.21, t=.003$ ). This seems to suggest that people with awareness alone, but without the capability of self-emotion appraisal, may not be free from the tendency to cling to their greed and distress.

Correlation analyses were conducted to examine the relationships among self-reported mindfulness (both body-mind-senses awareness and greed-distress un-clinging), rater-rated mindfulness (modified MACAM), and momentary mindfulness (experience sampling). The results show that self-reported body-mind-senses awareness was moderately associated with momentary 
mindfulness ( $r=.352$ ) but was not significantly related to rater-rated mindfulness $(r=.208)$. Self-reported greed-distress un-clinging was moderately correlated with rater-rated mindfulness $(r=.533)$ but was not significantly correlated with momentary mindfulness $(r=-.057)$.

\section{Association between awareness and un-clinging with mental health outcomes}

Further correlation analyses (Table 1) were conducted to examine the relationships between awareness, un-clinging and mental health outcomes. The results reveal that awareness was positively correlated with positive affect, emotional intelligence, daily spiritual experience and life satisfaction. Awareness was also negatively correlated with perceived stress. No relationship was found with physical distress, negative affect, stagnation or awareness. Un-clinging was found to be positively correlated with emotional intelligence and negatively correlated with physical distress, negative affect, stagnation and perceived stress.

Distinguishing meditators from non-meditators with awareness and un-clinging measures

In order to explore whether or not awareness and un-clinging distinguish meditators from non-meditators, t-tests were employed to evaluate the association of awareness and un-clinging with meditation experience (yes/no). No signifi-

20 cant differences were found between the awareness scores of meditators and non-meditators. However, for the un-clinging measure, there were significant differences found in the scores between meditators $(M=15.59, S D=3.75)$ and non-meditators $(M=13.37, S D=3.56)[t(206)=4.32, p<.001]$.

\section{Path analysis of awareness and un-clinging in regard to stress}

25 reduction via discernment and non-attachment

First, the correlations related to the dependent variable (perceived stress) and the independent variables (awareness, un-clinging, emotional intelligence and

Table 1. Correlations between awareness and un-clinging with mental health outcomes.

\begin{tabular}{lcc}
\hline & Awareness & Un-clinging \\
\hline Physical distress & -0.083 & $-0.244^{* *}$ \\
Negative affect & -0.120 & $-0.513^{* *}$ \\
Positive affect & $0.249^{* *}$ & $0.302^{* *}$ \\
Emotional intelligence & $0.392^{* *}$ & $0.325^{* *}$ \\
Stagnation & -0.125 & $-0.532^{* *}$ \\
Daily spiritual experience & $0.231^{* *}$ & 0.134 \\
Perceived stress & $-0.187^{* *}$ & $-0.533^{* *}$ \\
Life satisfaction & $0.171^{* *}$ & $0.153^{*}$ \\
\hline
\end{tabular}

"Significant at the 0.05 level; ${ }^{* *}$ Significant at the 0.01 level. 
stagnation over-attachment) were explored. All the relationships were found to be significant and in the expected directions. A multiple regression analysis was then conducted to predict perceived stress related by emotional intelligence and over-attachment. The model explained $66 \%$ of the variance regarding perceived stress, with self-emotion appraisal, regulation of emotion and over-attachment as the significant predictors. Another multiple regression analysis was conducted to predict over-attachment by self-emotion appraisal and the regulation of emotion. Both self-emotion appraisal $(\beta=-0.23, p<.01)$ and emotion regulation $(\beta=-0.44, p<.01)$ were found to be significant predictors of over-attachment.

Based on the above linear models, a path model from awareness and un-clinging towards perceived stress was constructed and evaluated. AMOS 18.0 (Arbuckle 2009) was employed to evaluate the path model. Five commonly reported fit indices were chosen to cover both absolute and incremental fit indices, which were relative chi-square (chi-square fit index divided by degrees of freedom, $\left.X^{2} / \mathrm{df}\right)$, comparative fit index (CFI), Tucker-Lewis index (TLI), root mean square error of approximation (RMSEA) and standardised root mean square residual (SRMR). Relative chi-square $\left(x^{2} / \mathrm{df}\right)$ was used instead of the chisquare statistic because of its hypersensitivity to sample size (Marsh, Balla, and McDonald 1988; Schumaker and Lomax 2004). Good model fit is indicated by $x^{2} /$ df below three, CFI and NNFI values greater than .90, and RMSEA and SRMR below .08 (Hu and Bentler 1999; McDonald and Ho 2002).

The results of the path model analysis are depicted in Figure 2. The fit indices were revealed to be good: $X^{2}=8.532 ; \mathrm{df}=5 ; X^{2} / \mathrm{df}=1.706 ; \mathrm{CFI}=.993 ; \mathrm{TLI}=.978$;

$25 \mathrm{RMSEA}=.059 ; \mathrm{SRMR}=.030$. All the estimated parameters were significant at the $p<0.01$ level. Variance explained by the model was $66 \%$. Overall, this suggests that the structural model successfully captures the relationships among the different variables.

\section{Discussion}

30 In response to the call from some scholars, notably Kabat-Zinn, the founder of MBSR (2003, 2011), to reinstate the Buddhist dharma in the conceptualisation of mindfulness, the current study examined the roles of awareness and un-clinging in mindfulness practice. Both awareness and un-clinging have been emphasised in Buddhist discourse as important facets of mindfulness. Using multiple assessment modalities, the results of this study show that awareness and un-clinging are distinct facets of mindfulness, and that un-clinging is indispensable in the improvement of mental health.

Our results show that un-clinging, which emphasises the ability to stand back from negative emotions, can be captured by semi-structured interviews 40 and rated by a rater. On the other hand, the present-moment awareness aspect of mindfulness, which focuses on the contingencies of participants' momentary 


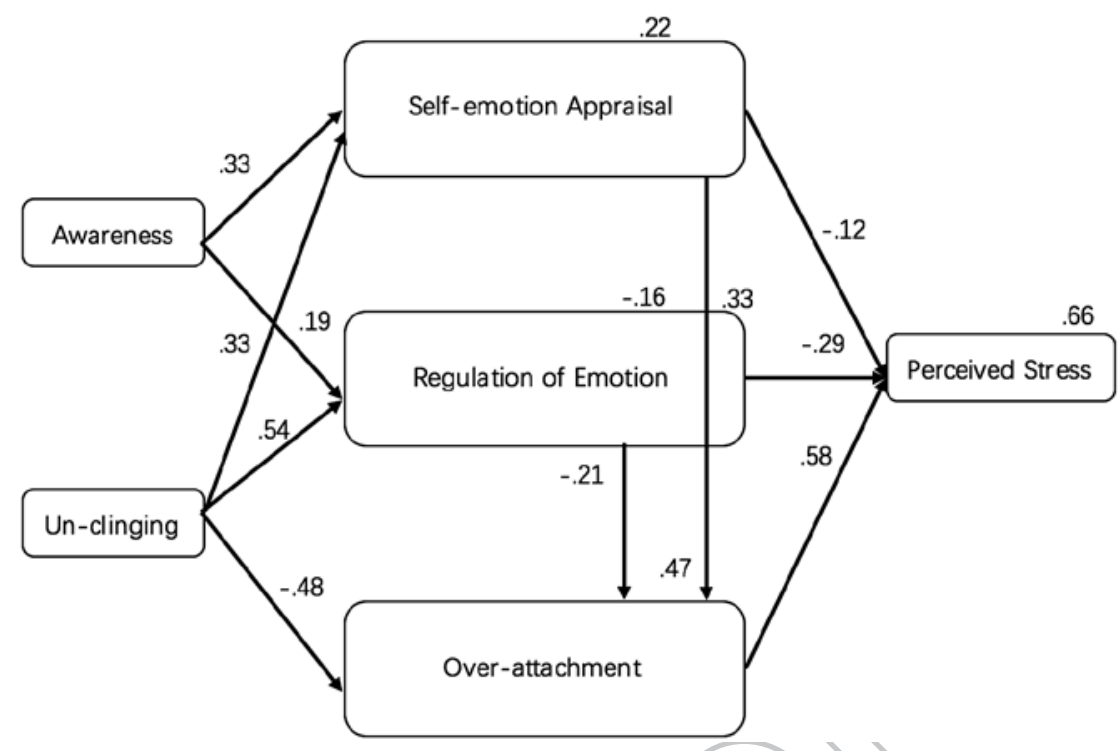

Figure 2. A simplified mindfulness model for stress reduction based on the original Buddha's mindfulness discourse. The good model-fit supports the Buddha's description of mindfulness training that practicing awareness and un-clinging can facilitate discernment towards psychological functioning (Self Emotion Appraisal and Emotion Regulation) and non-attachment to the external world (Stagnation Over-attachment), which can in turn lead to stress reduction. Self-emotion appraisal, emotion regulation and over-attachment fully mediate the relationship between un-clinging and perceived stress.

Notes: $X^{2}=8.532 ; \mathrm{df}=5 ; X^{2} / \mathrm{df}=1.706 ; \mathrm{CFI}=.993 ; \mathrm{TL}=.978 ; \mathrm{RMSEA}=.059 ; \mathrm{SRMR}=.030$; variance explained $=66 \%$.

mindfulness experiences, can be captured by experience sampling, using random prompts on mobile phones. The results suggest that awareness and un-clinging are two distinguishable domains of mindfulness experiences, with a non-significant correlation. In other words, people with high levels of awareness may still become over-attached to their own greed and distress, whereas people with low levels of awareness may still be able to let go of their own greed and distress. The results imply that mindfulness interventions need to consciously guide awareness training towards the direction of pursuing un-clinging, with a view to achieving a higher level of liberation from suffering.

Although both awareness and un-clinging were associated with emotional intelligence and perceived stress, un-clinging was also related to less stagnation, physical distress, and negative affect. The findings suggest that un-clinging is more closely related to the reduction of negative symptoms and support our hypothesis regarding un-clinging's greater affinity with relieving suffering, compared to its affinity with awareness.

Awareness was also found to be negatively related to un-clinging when controlling for self-emotion appraisal. People with high levels of awareness alone, 
without discerning, may be clinging even more to their own greed and distress. These findings highlight a potential problem within mindfulness practices that primarily focus on awareness training for live-the-moment peacefulness alone.

An interesting but not entirely unexpected result is that the level of bodymind-senses awareness cannot discriminate meditators from non-meditators, while un-clinging can. A plausible reason for this is that many modern and Buddhist meditations largely focus on awareness of breath and body, and much less on the senses and the mind (Brown, Ryan, and Creswell 2007; Ivanovski and Malhi 2007; Mikulas 2010). This finding also echoes the critique that many mindfulness practices are grounded in a watered-down understanding of awareness. In Buddhist mindfulness practice, awareness, discerning and un-clinging go hand-in-hand.

The resultant structural model captures the essence of the Buddha's mindfulness discourse, in that awareness and un-clinging can bring about discernment in regard to psychological functioning (Emotional Intelligence subscale - Self Emotion Appraisal and Emotion Regulation) and non-attachment to the external world (Stagnation subscale Over-Attachment), which can in turn lead to stress reduction. Self-emotion appraisal, emotion regulation and over-attachment fully mediate the relationship between un-clinging and perceived stress. According to the Buddha's mindfulness practice discourse, awareness alone is not enough to cultivate mental health and personal peace. Discernment, un-clinging (to the internal body, mind and senses), and non-attachment (to external world affairs and matters) are also needed. The Buddha defines mindfulness clearly in regard to both awareness and un-clinging, which bring about discernment and non-attachment:

A monk remains focused on the body ... feelings ... mind ... mental qualities ardent, alert, and mindful - putting aside greed and distress with reference to the world ... In this way, he remains focused both internally and externally on the body, feeling, mind, and mental objects; or he remains focused on the phenomenon of origination and passing away with regard to the body, feeling, mind, and mental objects; or his mindfulness that 'there is a body, feeling, mind, and mental qualities' is maintained to the extent of knowledge and remembrance. He remains independent, un-sustained by (not clinging to) anything in the world'. (Thanissaro 2011)

Most prevailing operationalisations and interventions that related to mindfulness lack discernment and un-clinging. Discernment involves an in-depth understanding of how stress and suffering arise and disappear (Four Noble Truths). Un-clinging may be viewed as a significant extension of 'decentering' (Teasdale et al. 2002; Hargus et al. 2010) and an even broader, more global and sustained shift in perspective, such that one experiences a continuous distancing between awareness and all perceptible physical and psychological experience. This includes distance from sensation and bodily experiences (such as visceral interception and proprioception), in addition to distance from thoughts and feelings. Such total distancing from all internal perceptible experience in 
turn brings non-attachment to the external world and causes a reduction of stress, according to the Buddha's mindfulness discourse.

\section{Limitations and future research}

This study is subject to several limitations. Most notably, the study relied on convenience samples, which might lead to sampling bias and limits the generalisability of the results. Further studies are advised to examine other populations, such as community adults, patients and people from different cultural groups and meditation traditions. It would also be valuable to adopt a longitudinal design that tracks the mindfulness scores and related mental health variables of participants going through different mindfulness-based interventions or Buddhist meditations, such as Vipassana or Zen.

\section{Conclusion}

Based on Buddhist discourse, this study examined the conceptualisation of mindfulness through distinguishing awareness and un-clinging. The results suggest that awareness and un-clinging are distinct but indispensable constructs in mindfulness practice. Our findings help re-contextualise and reinstate the Buddhist dharma in regard to the conceptualisation of mindfulness practice.

\section{Disclosure statement}

The authors declare that they have no conflict of interests.

\section{Notes on contributors}

Siu-man $\mathrm{Ng}$ is an associate professor in the Department of Social Work and Social Administration at The University of Hong Kong. His key research area is the application of traditional Chinese medicine (TCM) and philosophies in mental health work. Current research projects include operationalisation of stagnation (a concept from TCM) as a mental health construct, illness coping strategies in functional disorders (especially symptoms catastrophising and social hypervigilance), and welling-being and spirituality.

King Wo Chow is a postdoctoral fellow in the Department of Psychology at the Chinese University of Hong Kong. His research interest is about mindfulness and mental health. He's interested in developing mindfulness scales and interventions based on the original Buddha discourses.

Hi Po Lau is a postdoctoral fellow in the Department of Social Work and Social Administration at The University of Hong Kong. Her major research interest is mind/ body medicine and holistic health and mental health interventions. 
Qi Wang is a PhD student in the Department of Social Work and Social Administration at The University of Hong Kong. Her research interest is about spirituality and spiritual experiences.

\section{References}

Arbuckle, J. 2009. Amos 18 User's Guide. Chicago, IL: SPSS.

Baer, R. A. 2003. "Mindfulness Training as a Clinical Intervention: A Conceptual and Empirical Review." Clinical Psychology: Science and Practice 10: 125-143. doi:10.1093/ clipsy.bpg015.

Baer, R., ed. 2010. Assessing Mindfulness and Acceptance Processes in Clients: Illuminating the Theory and Practice of Change. Oakland, CA: Context Press/New Harbinger.

Baer, R. A., G. T. Smith, and K. B. Allen. 2004. "Assessment of Mindfulness by Selfreport: The Kentucky Inventory of Mindfulness Skills." Assessment 11: 191-206. doi:10.1177/1073191104268029.

Baer, R. A., G. T. Smith, J. Hopkins, J. Krietemeyer, and L. Toney. 2006. "Using Self-report Assessment Methods to Explore Facets of Mindfulness." Assessment 13: 27-45. doi:10.1177/1073191105283504.

Baer, R. A., G. T. Smith, E. Lykins, D. Button, J. Krietemeyer, S. Sauer, and J. M. G. Williams. 2008. "Construct Validity of the Five Facet Mindfulness Questionnaire in Meditating and Nonmeditating Samples." Assessment 15: 329-342. doi:10.1177/1073191107313003.

Bergomi, C., W. Tschacher, and Z. Kupper. 2013. "Measuring Mindfulness: First Steps Towards the Development of a Comprehensive Mindfulness Scale." Mindfulness 4: 18-32. doi:10.1007/s12671-012-0102-9.

Brown, K. W., and R. M. Ryan. 2003. "The Benefits of Being Present: Mindfulness and Its Role in Psychological Well-being." Journal of Personality and Social Psychology 84 (4): 822-848. doi:10.1037/0022-3514.84.4.822.

Brown, K.W., R. M. Ryan, and J. D. Creswell. 2007. "Addressing Fundamental Questions About Mindfulness." Psychological Inquiry 18 (4): 272-281. doi:10.1080/10478400701703344.

Brown, K. W., R. M. Ryan, and J. D. Creswell. 2007. "Mindfulness: Theoretical Foundations and Evidence for Its Salutary Effects." Psychological Inquiry 18: 211-237. doi:10.1080/10478400701598298.

Buchheld, N., P. Grossman, and H. Walach. 2001. "Measuring Mindfulness in Insight Meditation (Vipassana) and Meditation-Based Psychotherapy: The Development of the Freiburg Mindfulness Inventory (FMI)." Journal for Meditation and Meditation Research 1: 11-34.

Cardaciotto, L., J. D. Herbert, E. M. Forman, E. Moitra, and V. Farrow. 2008. “The Assessment of Present-moment Awareness and Acceptance:The Philadelphia Mindfulness Scale." Assessment 15: 204-233. doi:10.1177/1073191107311467.

Chiesa, A., and A. Serretti. 2009. "Mindfulness-based Stress Reduction for Stress Management in Healthy People: A Review and Meta-analysis." Journal of Alternative and Complementary Medicine 15: 593-600. doi:10.1089/acm.2008.0495.

Chiesa, A., and A. Serretti. 2010. "A Systematic Review of Neurobiological and Clinical Features of Mindfulness Meditations." Journal of Alternative and Complementary Medicine 15: 593-600. doi:10.1017/s0033291709991747.

Chow, K. W. 2015. "Measuring and Evaluating Mindfulness Based on Its Origin." PhD., The University of Hong Kong, Hong Kong. http://hub.hku.hk/bitstream/10722/221093/1/ FullText.pdf.

Cohen, S., T. Kamarck, and R. Mermelstein. 1983. "A Global Measure of Perceived Stress." Journal of Health and Social Behavior 24 (4): 385-396. doi:10.2307/2136404. 
Deikman, A. J. 1996. "I' Awareness." Journal of Consciousness Studies 3: 350-356.

Diener, E., R. A. Emmons, R. J. Larsen, and S. Griffin. 1985. "The Satisfaction with Life Scale.” Journal of Personality Assessment 49: 71-75.

Grossman, P. 2011. “Defining Mindfulness by 'How Poorly I Think I Pay Attention in Everyday Awareness' and Other Intractable Problems for Psychology's (Re)Invention of Mindfulness." Psychological Assessment 23 (4): 1034-40. doi:10.1037/a0022713.

Grossman, P., and N. T. Van Dam. 2011. "Mindfulness, by Any Other Name ... : Trials and Tribulations of Sati in Western Psychology and Science." Contemporary Buddhism 12: 219-239. doi:10.1080/14639947.2011.564841.

Grossman, P., L. Niemann, S. Schmidt, and H. Walach. 2004. "Mindfulness-based Stress Reduction and Health Benefits: A Meta-analysis." Journal of Psychosomatic Research 57: 35-43. doi:10.1016/S0022-3999(03)00573-7.

Hargus, E., C. Crane, T. Barnhofer, and J. M. G. Williams. 2010. "Effects of Mindfulness on Meta-awareness and Specificity of Describing Prodromal Symptoms in Suicidal Depression." Emotion 10: 34-42.

Hayes, S. C., and K. G. Wilson. 2003. "Mindfulness: Method and Process." Clinical Psychology: Science and Practice 10: 161-165. doi:10.1093/clipsy/bpg018.

Hayes, S. C., K. Strosahl, and K. G. Wilson. 1999. Acceptance and Commitment Therapy: An Experiential Approach to Behavior Change. New York: Guilford Press.

Hofmann, S. G., A. T. Sawyer, A. A. Witt, and D. Oh. 2010."The Effect of Mindfulness-based Therapy on Anxiety and Depression: A Meta-Analytic Review." Journal of Consulting and Clinical Psychology 78 (2): 169-183. doi:10.1037/a0018555.

Hu, L. T., and P. M. Bentler. 1999. "Cutoff Criteria for Fit Indexes in Covariance Structure Analysis: Conventional Criteria Versus New Alternatives." Structural Equation Modeling 6: 1-55. doi:10.1080/10705519909540118.

Ivanovski, B., and G. Malhi. 2007. “The Psychological and Neurophysiological Concomitants of Mindfulness Forms of Meditation." Acta Neuropsychiatrica 19 (2): 76-91. doi:10.1111/ j.1601-5215.2007.00175.x.

Jha, A., E. Stanley, A. Kiyonaga, L. Wong, and L. Gelfand. 2010. “Examining the Protective Effects of Mindfulness Training on Working Memory Capacity and Affective Experience." Emotion 10 (1): 54-64. doi:10.1037/a0018438.

Kabat-Zinn, J. 1982. "An Outpatient Program in Behavioral Medicine for Chronic Pain Patients Based on the Practice of Mindfulness Meditation: Theoretical Considerations and Preliminary Results." General Hospital Psychiatry 4: 33-47. doi:10.1016/01638343(82)90026-3.

Kabat-Zinn, J.2003. "Mindfulness-based Interventions in Context: Past, Present and Future." Clinical Psychology: Science and Practice 10: 144-156. doi:10.1093/clipsy. bpg016.

Kabat-Zinn, J. 2011. "Some Reflections on the Origins of MBSR, Skilful Means, and the Trouble with Maps." Contemporary Buddhism 11 (1): doi:10.1080/14639947.2011.56 4844.

Komagata, N., and S. Komagata. 2010. Mindfulness and Flow Experience. http://nobo. komagatta.net/pub/Komagata+10-MIndfulnessFlow.html.

Linehan, M. M. 1993. Cognitive-behavioral Treatment of Borderline Personality Disorder. New York: Guilford Press.

Marsh, H. W., J. R. Balla, and R. P. McDonald. 1988. “Goodness-of-fit Indexes in Confirmatory Factor Analysis: The Effect of Sample Size." Psychological Bulletin 103 (3): 391. doi:10.1037/0033-2909.103.3.391.

McDonald, R. P., and M. H. R. Ho. 2002. "Principles and Practice in Reporting Structural Equation Analyses." Psychological Methods 7: 64-82. doi:10.1037/1082-989x.7.1.64. 
Mendis, N. K. G. 1993. The Questions of King Milianda:An Abridgment of the Milindapañha. Kandy: Buddhist Publication Society.

Mikulas, W. 2010. "Mindfulness: Significant Common Confusions." Mindfulness 2: 1-7. doi:10.1007/s12671-010-0036-z.

Mooneyham, B., M. Mrazek, A. Mrazek, and J. Schooler. 2016. "Signal or Noise: Brain Network Interactions Underlying the Experience and Training of Mindfulness." Annals of the New York Academy of Sciences 1369 (1): 240-256. doi:10.1111/nyas.13044.

Moore, R. G., H. Hayhurst, and J. D. Teasdale. 1996. “Measure of Awareness and Coping in Autobiographical Memory: Instructions for Administering and Coding." Unpublished Manuscript., Department of Psychiatry, University of Cambridge, Cambridge.

Ng, S. M. 2013. "Validation of the 10-item Chinese Perceived Stress Scale in Elderly Service Workers: One-factor versus Two-factor Structure." BMC Psychology 1: 9. doi:10.1186/2050-7283-1-9.

Ng, S. M., J. K. Y. Yau, C. L. W. Chan, C. H. Y. Chan, and D. Y. F. Ho. 2005. "The Measurement of Body-mind-spirit Well-being: Toward Multidimensionality and Transcultural Applicability." Journal of Social Work in Health Care 41: 33-52. doi:10.1300/ j010v41n01_03.

Ng, S. M., T. C. T. Fong, E. Y. L. Tsui, F. S. W. Au-Yeung, and S. K. W. Law. 2009."Validation of the Chinese Version of Underwood's Daily Spiritual Experience Scale - Transcending Cultural Boundaries?" International Journal of Behavioral Medicine 16 (2): 91-97. doi:10.1007/s12529-009-9045-5.

Ng, S. M., T. C. T. Fong, X. L. Wang, and Y. J. Wang. 2012. “Confirmatory Factor Analysis of the Stagnation Scale - A Traditional Chinese Medicine Construct Operationalized for Mental Health Practice." International Journal of Behavioral Medicine 19 (2): 228-233.

Nyanaponika, Thera. 1962. The Heart of Buddhist Meditation. New York: Weiser.

Rahula, W. 1974. What the Buddha Taught. New York: Grove Press.

Rapgay, L., and A. Bystrisky. 2009. "Classical Mindfulness: An Introduction to Its Theory and Practice for Clinical Application." Annals of the New York Academy of Science 1172: 148-162. doi:10.1111/j.1749-6632.2009.04405.x.

30 Roemer, L., and S. M. Orsillo. 2003. "Mindfulness: A Promising Intervention Strategy in Need of Further Study." Clinical Psychology 10 (2): 172-178. doi:10.1093/clipsy.bpg020.

Sahdra, B. K., P. R. Shaver, and K. W. Brown. 2010. "A Scale to Measure Nonattachment: A Buddhist Complement to Western Research on Attachment and Adaptive Functioning." Journal of Personality Assessment 92: 1-12. doi:10.1080/00223890903425960.

35 Schumaker, R. E., and R. G. Lomax. 2004. A Beginner's Guide to Structural Equation Modeling. 2nd ed. Mahwah, NJ: Lawrence Erlbaum.

Schutte, N. S., I. M. Malouff, L. E. Hall, D. J. Haggerty, J. T. Cooper, C. J. Golden, and L. Dornheim. 1998. "Development and Validation of a Measure of Emotional Intelligence." Personality and Individual Differences 25 (2): 167-177.

Segal, Z. V., J. M. G. Williams, and J. D. Teasdale. 2002. Mindfulness-based Cognitive Therapy for Depression: A New Approach to Preventing Relapse. New York: Guildford Press.

Smith, G. T., S. Fischer, and S. M. Fister. 2003. "Incremental Validity Principles in Test Construction." Psychological Assessment 15: 467-477. doi:10.1037/1040-3590.15.4.467.

Smith, G. T., S. Fischer, M. A. Cyders, A. M. Annus, N. S. Spillane, and D. M. McCarthy. 2007. "On the Validity and Utility of Discriminating among Impulsivity-like Traits." Assessment 14: 155-170. doi:10.1177/1073191106295527.

Teasdale, J. D., R. G. Moore, H. Hayhurst, M. Pope, S. Williams, and Z. V. Segal. 2002. "Meta-cognitive Awareness and Prevention of Relapse in Depression: Empirical Evidence." Journal of Consulting and Clinical Psychology 70: 278-287. doi:10.1037/0022006x.70.2.275. 
Thanissaro, Bhikkhu. 2011. Maha-Satipatthana Sutta: The Great Frames of Reference. http:// www.accesstoinsight.org/tipitaka/dn/dn.22.0.than.html.

Underwood, J. G., and J. A. Teresi. 2002. "The Daily Spiritual Experience Scale: Development, Theoretical Description, Reliability, Exploratory Factor Analysis, and Preliminary Construct Validity Using Health-related Data." Annals of Behavioral Medicine 24 (1): 22-33. doi:10.1207/s15324796abm2401_04.

Vera-Villarroel, P., M. A. Urzúa, P. P. K. Celis-Atenas, and J. Silva. 2012. “Evaluation of Subjective Well-being: Analysis of the Satisfaction with Life Scale in Chilean Population." Universitas Psychologica 11 (3): 719-727. http://www.scielo.org.co/scielo. php?script=sci_arttext\&pid=S1657-92672012000300003\&lng=en\&tlng=en .

Walach, H., N. Buchheld, V. Buttenmüller, N. Kleinknecht, and S. Schmidt. 2006. "Measuring Mindfulness - The Freiburg Mindfulness Inventory (FMI)." Personality and Individual Differences 40 (8): 1543-1555. doi:10.1016/j.paid.2005.11.025.

Wong, C. S., and K. S. Law. 2002. "The Effects of Leader and Follower Emotional Intelligence on Performance and Attitude: An Exploratory Study." The Leadership Quarterly 13 (3): 243-274. doi:10.1207/s15324796abm2401_04.

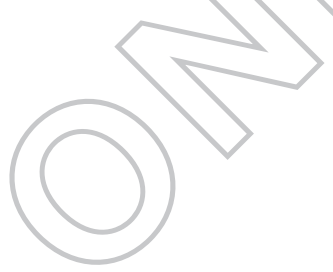

